\title{
OVERALL EQUIPMENT EFFECTIVENESS EVALUATION OF MAINTENANCE STRATEGY FOR RENTED EQUIPMENT
}

\author{
Ade Supriatna, Moses Laksono Singgih, Erwin Widodo, Nani Kurniati
}

Figure 1 shows the effect of shape parameter $(\beta)$ and scale parameter $(\alpha)$ on the estimated total maintenance charge optimal $\left(C^{*}\right)$. Enhanced form parameters will increase the total estimated maintenance charge. For example, if $(\beta, \alpha, L)=(1,5,0,5,2)$ will cause $C_{0}=452.08$ and $C^{*}=$ 312.420 and if the shape parameter is increased $(\beta, \alpha, L)=(2,0,5,2)$ then $C_{0}=452.08$ and $C^{*}=350.348$. Likewise scale parameters, if $(\beta, \alpha, L)=(1,5,1,2)$ then $C_{0}=1278.67$ and $C^{*}=$ 621.241. If the lessor does not perform PM, the increase in $\alpha$ affects the estimated total maintenance charge. However, if the lessor does PM, $\alpha$ and $\beta$ affect the total estimated maintenance charge. Therefore, the lessor must consider these two parameters when combining $\mathrm{CM}$ and PM in the maintenance strategy. The blue line shows $\alpha=0.5$ and the red line shows $\alpha=$ 1.

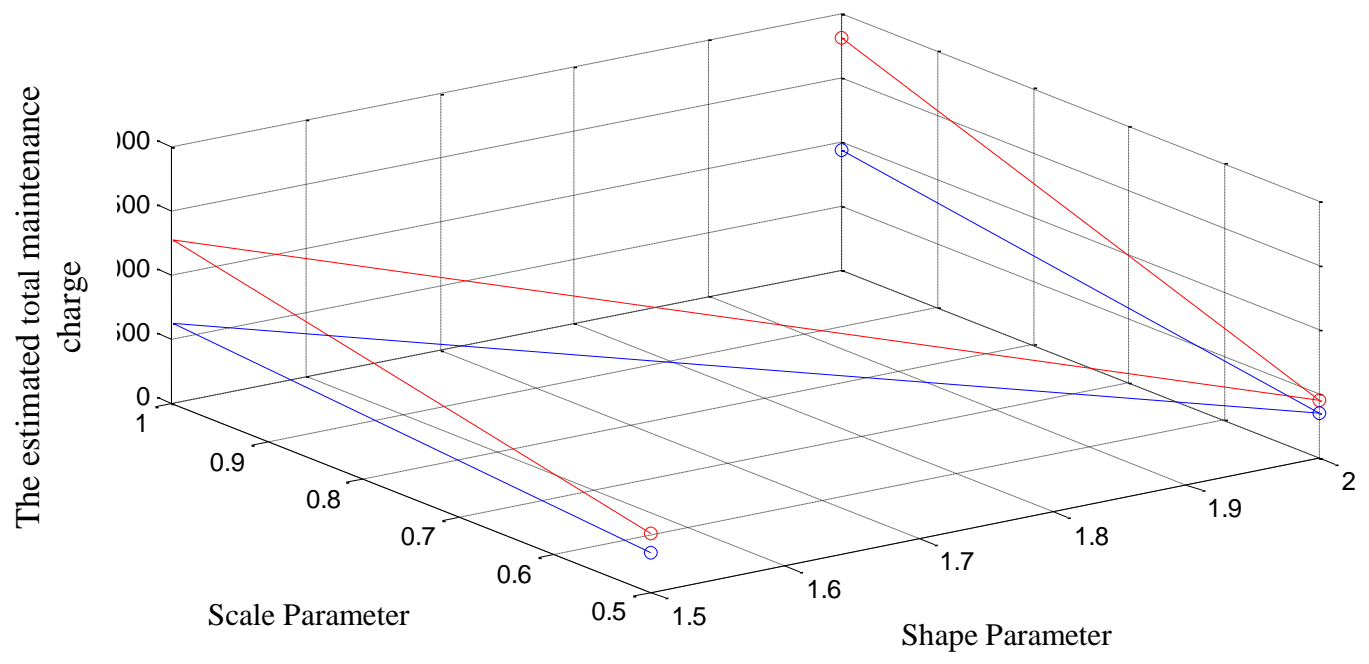

Figure 1. The effect of $\beta$ and $\alpha$ on $C^{*}$

Figure 2 shows that a maintenance strategy without PM has a higher estimated total maintenance charge than with PM. In the same condition, $(\beta, \alpha, L)=(1.5,0.5,2)$, the maintenance strategy without PM has $C_{0}=452.08$. However, if the maintenance strategy is a combination of $\mathrm{CM}$ and PM has $C^{*}=312.420$ making it more efficient $(\Delta) 30.893 \%$. Meanwhile, in conditions $(\beta, \alpha, \mathrm{L})$ $=(1.5,0.5,4)$, the maintenance strategy without PM has $C_{0}=1278.67$. However, if the maintenance strategy is a combination of $\mathrm{CM}$ and PM has $C^{*}=583,323$. The maintenance strategy without PM is plotted with the red line and the maintenance strategy with PM is plotted with the blue line. The combination of CM and PM can reduce the amount of failure and penalties thereby minimizing the estimated total maintenance charge. 


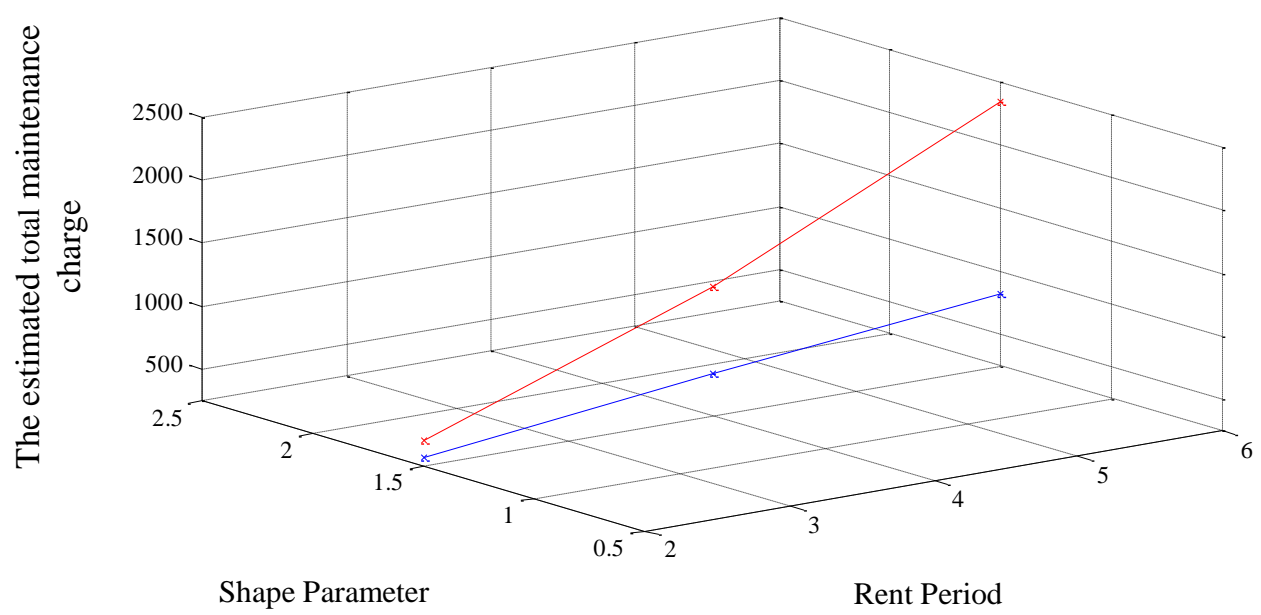

Figure 2. Comparison of maintenance strategies without PM and with PM.

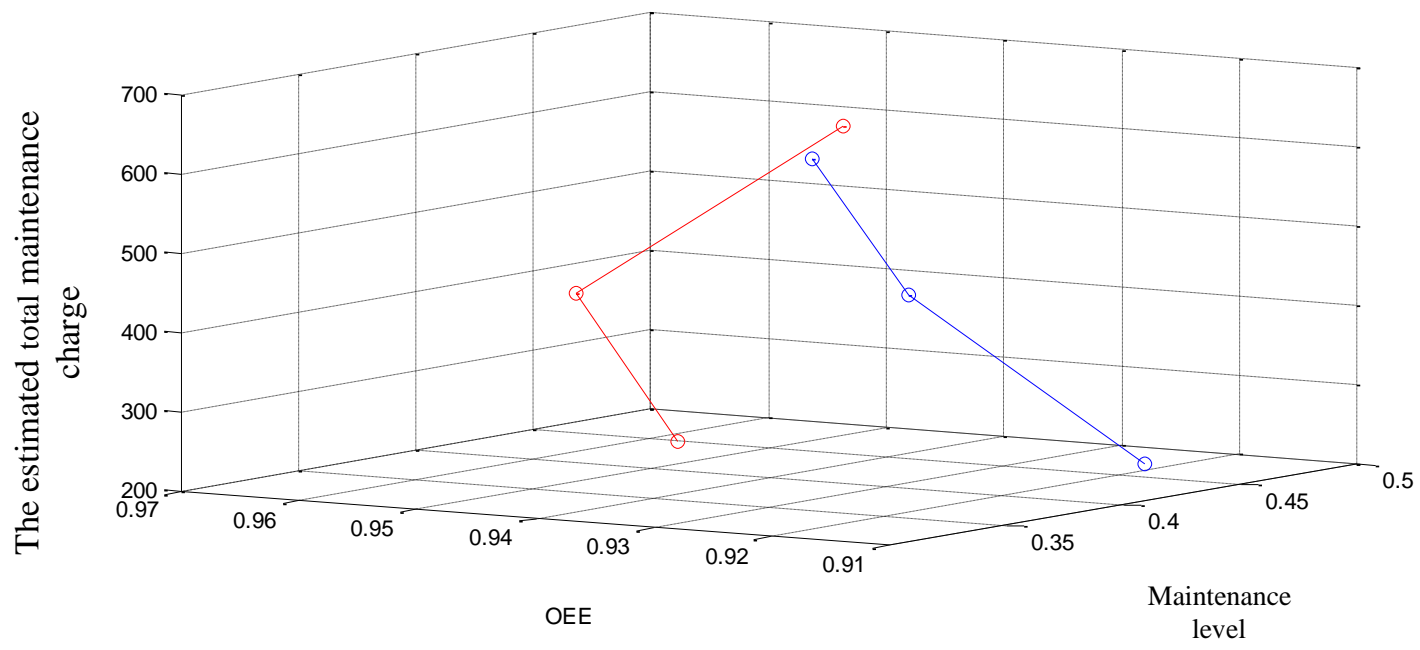

Figure 3. The relationship between maintenance level $(\delta)$ with OEE and the estimated total maintenance cost optimal $\left(C^{*}\right)$

Figure 3 shows the relationship of maintenance degree $(\delta)$ with the estimated total maintenance charges $(C)$ and OEE. When the maintenance degree and repair time increases, charges tend to rise as well, though OEE does not necessarily increase because it is influenced by many factors, such as rent period, total of PM, amount of failure etc. The repair time, $\tau=1$ is plotted with red line and $\tau=2$ in blue. 